\title{
Language-developmental trajectory in autism
}

\author{
Data collection, social communication, statistical \\ learning and autistic traits
}

\author{
Jeannette Schaeffer and Ileana Grama \\ University of Amsterdam
}

\section{October, 2021}

Prevost \& Tuller (2022, henceforth P\&T) present an interesting and much needed scoping review on bilingual language development and autism, putting its finger on several important issues and shortcomings in studies on (monolingual and bilingual) language (development) and autism. In this response to P\&T we touch on several topics that have recently inspired discussions in our Languagein-Autism ( $\mathrm{LiA}$ ) lab in Amsterdam, including language-developmental trajectory in relation to data collection, social communication, statistical learning, and autistic traits.

\section{Data collection}

P\&T argue that bilingual development in autistic children ${ }^{1}$ is different from typically developing (TD) children. We believe monolingual development is different in autistic children as well. For example, the fact that there are no age effects regarding several morphosyntactic and pragmatic phenomena in a group of 6-14-year-old monolingual Dutch-speaking autistic children (Schaeffer, 2021) indicates a language-developmental difference in comparison to TD children.

Furthermore, even in cases in which autistic children's experimental language scores do not differ from their TD peers', it might be that the processes leading to their responses are different. In fact, autistic individuals without intellectual disability are often particularly good at controlled lab tests, while it is not clear

1. The current commentary uses 'disability-first' terms throughout, which is favored by autistic individuals and their parents. (Kenny et al., 2015).

¿ Available under the CC BY 4.0 license. ๑ John Benjamins Publishing Company 
whether they can generalize these 'lab skills' to reality: recently, for instance, an analysis of spontaneous speech in a large sample of children with ASD showed syntactic abilities ranging from severe deficits to mild deficits to no deficits at all (Wittke et al., 2017).

Therefore, our task as researchers is to develop ways to collect data from autistic children in a more natural and ecologically valid way, revealing more of the processing underlying the experimental response in a more realistic situation. Aside from spontaneous speech analyses, a 'living lab' may be the answer to this problem, that is particularly prominent in autism research. A living lab is a usercentered eco-system, often operating in a socially and physically restricted context (campus, city, apartment building, school, home, ...) (Almirall \& Wareham, 2011, a.o.). Besides the inclusion of innovative measuring technology, living labs also crucially include members of the investigated population, in our case, autistic individuals, not only as research participants, but also as co-creators of research questions and experimental design. Although we fully embrace this idea, there are many questions to be answered first, varying from how to ensure that the participation of autistic individuals as co-creators is fully representative of the entire spectrum (including, for instance, minimally verbal autistic people) to what technology exactly to use and how.

A more accessible attempt at an ecologically valid testing environment for language in autism may be the 'Coloring Book Method' (Pinto \& Zuckerman, 2019). This is a comprehension task similar to Picture Selection except it does not require the child to select from a limited set of explicit options (which may provide clues to the purpose of the task). Instead, children are given instructions to color items in a visual array that contains many implicit alternatives (Figure 2).

Our lab, in collaboration with Pinto and Zuckerman, are using the Coloring Book Method to examine the computation of scalar implicatures (by autistic and TD children), as in the sentence Some candles are burning (implicating that not all candles are burning). Recent studies have used a Picture Selection Task (Foppolo et al., 2021; Mazzaggio et al., 2021; Stiller, Goodman \& Frank, 2015), with a limited set of alternatives as in Figure 1. These explicit alternatives may simultaneously (i) increase task demands, as children consider the compatibility of each alternative with the statement, and (ii) inflate performance as children are explicitly presented with the terms of the scale (none, some/not all, all), and given few options for interpretation.

Our ongoing study employs a Coloring Book task, as in Figure 2. The child may color one, two, three, four or all five of the monkeys (or choose to color nothing at all, or color some of the monkeys red and some blue, etc.). The alternatives are numerous and implicit, eliminating the confounds above. Although previous studies show mixed findings on the ability of autistic children to com- 

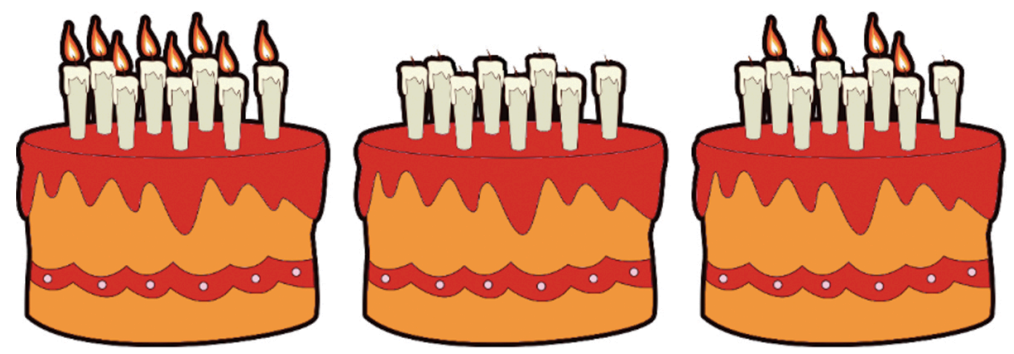

Figure 1. Picture selection task: "Some candles are burning"

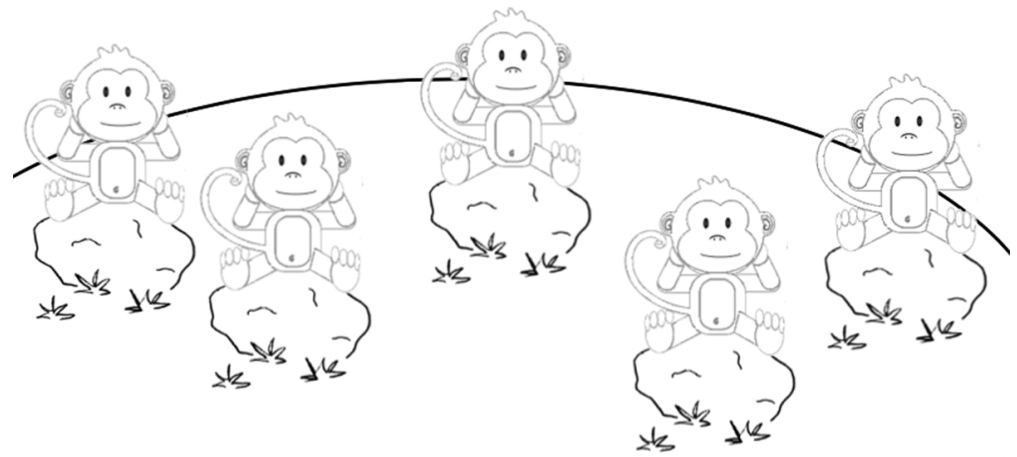

Figure 2. Coloring book: "Some monkeys are red"

pute scalar implicatures (Chanchaochai, 2019; Chevallier et al., 2010; Chin, 2017; Hochstein, Bale \& Barner, 2017; Mazzaggio et al., 2021; Pastor-Cerezuela et al., 2018; Schaeken et al., 2018; Su \& Su, 2015), we believe the conflicting findings could, in part, be attributed to the experimental methods used.

\section{Social communication and statistical learning}

According to the Diagnostic and Statistical Manual of Mental Disorders (DSM$\mathrm{V}$ ), autistic individuals have persistent deficits in social interaction and communication (American Psychological Association, 2013). If social communication is an important driver of typical language acquisition (Goldberg, 2003, 2013), the question is how (verbal) autistic children acquire language. Based on this, Kissine (2021) argues that the often successful acquisition of structural language, but also of pragmatics relying on egocentric perspective only by autistic children reveals that these linguistic skills can be acquired without socio-communicative interaction. The next question is whether such language acquisition (by autistic children) 
is grounded in a domain-specific genetic predisposition for language and/or in domain-general statistical learning skills.

Although a recent meta-study found no evidence for a statistical learning deficit in ASD (Obeid et al., 2016), many studies have found deficits (Scott-Van Zeeland et al., 2010, a.o.), advantages (Roser et al., 2015), or simply differences in the learning processes of ASD individuals (Jeste et al., 2015; Jones et al., 2018; Zwart et al., 2017). Studies are rare that examine individual differences in statistical learning in ASD, correlating them either to language abilities (Haebig et al., 2017), or autistic traits (Jones et al., 2018; Parks et al., 2020; Zwart, Visser \& Maes, 2018).

Preliminary findings in a recent study in our lab show that adults who report an autism diagnosis, or individuals in the Broader Autism Phenotype (as indicated by their poor scores on the Social Responsiveness Scale, SRS, Constantino \& Gruber, 2012) in fact show superior performance in a visual-motor statistical learning task (where the sequence was a Fibonacci grammar, see Vender et al. 2019, 2020) - namely, they show robust detection of both simple and more complex sequential patterns, where the TD group shows learning only of the simpler pattern (see Zwart et al. 2018 for a similar finding). Given that these individuals showed ceiling performance on our language tasks, we suggest that their strong language may have been developmentally supported by strong statistical learning abilities, acting as a protective factor against the negative effect of the social deficit. If this is the case, we predict that future research will show that ASD individuals with poorer language abilities (irrespective of IQ) will also show poorer statistical learning.

In short, we believe statistical learning is an important component of language in autism, and that individual differences in statistical learning show interesting links to language and autistic traits. This does not, of course, inform the question regarding a genetic predisposition for language acquisition. It may be the case that autistic children rely more on statistical learning than on social communication in the interplay with a potential genetic predisposition for language than TD children.

In addition, some evidence also exists of advantages in statistical learning for bilinguals (see Bulgarelli, Lebkuecher \& Weiss, 2018 for a review), suggesting that this unexplored interaction between autism, bilingualism and statistical learning is a worthy avenue for future research to pursue. 


\section{Autistic traits}

Finally, P\&T discuss the heterogeneity within autism (Section 1.3; see Lombardo et al., 2019). Heterogeneity results not only from autism being a spectrum, but the official diagnosis of autism also varies per country, region and even per diagnosing authority (psychiatrist, psychologist...), as became clear during the LACA Practitioners Meeting held in Milan in 2018. Furthermore, if repetitive behavior is the decisive factor for autism diagnosis, while social communication is less affected, this may have less of an effect on language (development). We therefore feel that using a measure of autistic traits in studies on language (be it mono- or multilingual) development in autism rather than official autism diagnosis is justified, and may predict more realistically what effect autism traits have on language (development). Tools to measure autistic traits include the ADI-R (Lord et al., 1994), the ADOS (Lord et al., 1999), or (for researchers who are not formally trained on these measures) the SRS (Constantino \& Gruber, 2012) or the Autism Quotient (Baron-Cohen et al., 2001).

Concluding, we have proposed a more ecologically valid way to collect data in autism (compared to the existing methods from language acquisition research), we have argued that statistical learning may play an important role and act as a protective factor in language acquisition by autistic children (particularly, perhaps, in bilingual autistic children), and that it is justified to create participant groups for language research based on autistic traits rather than exclusively on official autism diagnosis.

\section{References}

American Psychiatric Association. (2013). Autism Spectrum disorders. In Diagnostic and statistical manual of mental disorders (5th ed.). https://doi.org/10.1176/appi.books.9780890425596

Almirall, E., \& Wareham, J. (2011). Living Labs: arbiters of mid-and ground-level innovation. Technology Analysis \& Strategic Management, 23(1), 87-102. https://doi.org/10.1080/09537325.2011.537110

Baron-Cohen, S., Wheelwright, S., Skinner, R., Martin, J., \& Clubley, E. (2001). The autismspectrum quotient (AQ): Evidence from Asperger syndrome/high-functioning autism, males and females, scientists and mathematicians. Journal of autism and developmental disorders, 31(1), 5-17. https://doi.org/10.1023/A:1005653411471

Bulgarelli, F., Lebkuecher, A.L., \& Weiss, D. J. (2018). Statistical learning and bilingualism. Language, speech, and hearing services in schools, 49(3S), 740-753. https://doi.org/10.1044/2018_LSHSS-STLT1-17-0139

Chanchaochai, N. (2019). Language Profiles of Thai Children with Autism: Lexical, Grammatical, and Pragmatic Factors (Doctoral dissertation, University of Pennsylvania). 
Chevallier, C., Wilson, D., Happé, F., and Noveck, I. (2010). Scalar inferences in autism spectrum disorders. Journal of Autism and Developmental Disorders, 40, 1104-1117. https://doi.org/10.1007/s10803-010-0960-8

Chin, Iris. (2017). Variability in Pragmatic Abilities in Children with Autism Spectrum Disorder (Doctoral Dissertation, University of Connecticut).

Constantino, J.N., \& Gruber, C.P. (2012). Social responsiveness scale: SRS-2. Western Psychological Services.

Foppolo, F., Mazzaggio, G., Panzeri, F., \& Surian, L. (2021). Scalar and ad-hoc pragmatic inferences in children: guess which one is easier. Journal of Child Language, $48(2)$, 350-372. https://doi.org/10.1017/S030500092000032X

Gernsbacher, M.A., \& Yergeau, M. (2019). Empirical failures of the claim that autistic people lack a theory of mind. Archives of Scientific Psychology, 7(1), 102-118. https://doi.org/10.1037/arc0000067

Goldberg, A. E. (2003). Constructions: a new theoretical approach to language. Trends in Cognitive Sciences, 7, 219-224. https://doi.org/10.1016/S1364-6613(03)00080-9

Goldberg, A.E. (2013). Constructionist approaches. The Oxford Handbook of Construction Grammar, ed. by Thomas Hoffman and Graeme Trousdale. 15-31. Oxford University Press.

Haebig, E., Saffran, J.R., \& Ellis Weismer, S. (2017). Statistical word learning in children with autism spectrum disorder and specific language impairment. Journal of Child Psychology and Psychiatry, 58(11), 1251-1263. https://doi.org/10.1111/jcpp.12734

Hochstein, L., Bale, A., \& Barner, D. (2017). Scalar implicature in absence of epistemic reasoning? The case of Autism Spectrum Disorder. Language Learning and Development, 14(3), 224-240. https://doi.org/10.1080/15475441.2017.1343670

Jeste, S. S., Kirkham, N., Senturk, D., Hasenstab, K., Sugar, C., Kupelian, C., Baker, E., Sanders, A. J., Shimizu, C., Norona, A., Paparella, T., Freeman, S. F. N. \& Johnson, S.P. (2015). Electrophysiological evidence of heterogeneity in visual statistical learning in young children with ASD. Developmental science, 18(1), 90-105. https://doi.org/10.1111/desc.12188

Jones, R.M., Tarpey, T., Hamo, A., Carberry, C., Brouwer, G., \& Lord, C. (2018). Statistical Learning is Associated with Autism Symptoms and Verbal Abilities in Young Children with Autism. Journal of autism and developmental disorders, 48(10), 3551-3561. https://doi.org/10.1007/s10803-018-3625-7

Kenny, L., Hattersley, C., Molins, B., Buckley, C., Povey, C., and Pellicano, E. (2015). Which terms should be used to describe autism? Perspectives from the UK autism community. Autism, 20, 442-462. https://doi.org/10.1177/1362361315588200

Kissine, M. (2021). Autism, constructionism, and nativism. Language, 97(3), 139-160. https://doi.org/10.1353/lan.2021.0055

LACA (Language Abilities in Children with Autism) Practitioners Meeting. Milan, (2018). http://laca.humanities.uva.nl/wp/index.php/2018/o9/26/laca-meeting-milan-15-january2018/

Lombardo, M.V., Lai, M.C., \& Baron-Cohen, S. (2019). Big data approaches to decomposing heterogeneity across the autism spectrum. Molecular psychiatry, 24(10), 1435-1450. https://doi.org/10.1038/s41380-018-0321-o 
Lord, C., Rutter, M., Le Couteur, A. (1994). Autism Diagnostic Interview - Revised: A revised version of a diagnostic interview for caregivers of individuals with possible pervasive developmental disorders. Journal of Autism and Developmental Disorders, 24, 659-685. https://doi.org/10.1007/BF02172145

Lord, C., Risi, S., Lambrecht, L.K., Cook, E.H., Leventhal, B.L., DiLavore, P.C., Pickles, A., Rutter, M. (1999). The Autism Diagnostic Observation Schedule - Generic: A standard measure of social and communication deficits associated with the spectrum of autism. Journal of Autism and Developmental Disorders, 30, 205-223. https://doi.org/10.1023/A:1005592401947

Mazzaggio, G., Foppolo, F., Job, R., \& Surian, L. (2021). Ad-hoc and scalar implicatures in children with autism spectrum disorder. Journal of Communication Disorders, 9o, Article 106089. https://doi.org/10.1016/j.jcomdis.2021.106089

Obeid, R., Brooks, P.J., Powers, K.L., Gillespie-Lynch, K., \& Lum, J.A. (2016). Statistical learning in specific language impairment and autism spectrum disorder: A meta-analysis. Frontiers in psychology, 7, 1245. https://doi.org/10.3389/fpsyg.2016.01245

Parks, K. M., Griffith, L.A., Armstrong, N. B., \& Stevenson, R.A. (2020). Statistical Learning and Social Competency: The Mediating Role of Language. Scientific reports, 10(1), 1-15. https://doi.org/10.1038/s41598-020-61047-6

Pastor-Cerezuela, G., Tordera Yllescas, J.C., González-Sala, F., Montagut-Asunción, M., \& Fernández-Andrés, M.I. (2018). Comprehension of generalized conversational implicatures by children with and without Autism Spectrum Disorder. Frontiers in Psychology, 9, 272. https://doi.org/10.3389/fpsyg.2018.00272

Pinto, M., \& Zuckerman, S. (2019). Coloring Book: A new method for testing language comprehension. Behavior research methods, 51(6), 2609-2628. https://doi.org/10.3758/s13428-018-1114-8

Prevost, P., \& Tuller, L. (2022). Bilingual language development in autism. Linguistic Approaches to Bilingualism, 12(1).

Roser, M.E., Aslin, R.N., McKenzie, R., Zahra, D., \& Fiser, J. (2015). Enhanced visual statistical learning in adults with autism. Neuropsychology, 29(2), 163. https://doi.org/10.1037/neuoooo137

Schaeffer, J. (2021). The influence of cognitive abilities on article choice and scrambling performance in Dutch-speaking children with autism. Language Acquisition, 28(2), 166-194. https://doi.org/10.1080/10489223.2020.1724293

Schaeken, W., Van Haeren, M., \& Bambini, V. (2018). The Understanding of Scalar Implicatures in Children With Autism Spectrum Disorder: Dichotomized Responses to Violations of Informativeness. Frontiers in Psychology, 9, 1266. https://doi.org/10.3389/fpsyg.2018.01266

Scott-Van Zeeland, A.A., McNealy, K., Wang, A.T., Sigman, M., Bookheimer, S.Y., \& Dapretto, M. (2010). No neural evidence of statistical learning during exposure to artificial languages in children with autism spectrum disorders. Biological psychiatry, 68(4), 345-351. https://doi.org/10.1016/j.biopsych.2010.01.011

Stiller, A.J., Goodman, N. D., \& Frank, M.C. (2015). Ad-hoc implicature in preschool children. Language Learning and Development, 11(2), 176-190. https://doi.org/10.1080/15475441.2014.927328

Vender, M., Krivochen, D. G., Phillips, B., Saddy, D., \& Delfitto, D. (2019). Implicit learning, bilingualism, and dyslexia: Insights from a study assessing AGL with a modified Simon Task. Frontiers in psychology, 10, 1647. https://doi.org/10.3389/fpsyg.2019.01647 
Vender, M., Krivochen, D. G., Compostella, A., Phillips, B., Delfitto, D., \& Saddy, D. (2020). Disentangling sequential from hierarchical learning in Artificial Grammar Learning: Evidence from a modified Simon Task. Plos one, 15(5), e0232687. https://doi.org/10.1371/journal.pone.0232687

Wittke, K., Mastergeorge, A.M., Ozonoff, S., Rogers, S. J., \& Naigles, L. R. (2017). Grammatical language impairment in autism spectrum disorder: Exploring language phenotypes beyond standardized testing. Frontiers in psychology, 8, 532. https://doi.org/10.3389/fpsyg.2017.00532

Zwart, F.S., Vissers, C.T.W., van der Meij, R., Kessels, R. P., \& Maes, J.H. (2017). Autism: Too eager to learn? Event related potential findings of increased dependency on intentional learning in a serial reaction time task. Autism Research, 1o(9), 1533-1543. https://doi.org/10.1002/aur.1802

Zwart, F. S., Vissers, C.T.W., \& Maes, J.H. (2018). The association between sequence learning on the serial reaction time task and social impairments in Autism. Journal of autism and developmental disorders, 48(8), 2692-2700. https://doi.org/10.1007/s10803-018-3529-6

\section{Address for correspondence}

Jeannette Schaeffer

University of Amsterdam

PO Box 1642

Amsterdam 1000 BP

Netherlands

J.C.Schaeffer@uva.nl

https://orcid.org/oooo-ooo1-5613-8242

\section{Co-author information}

Ileana Grama

University of Amsterdam

i.c.grama@uva.nl

\section{Publication history}

Date received: 15 September 2021

Date accepted: 19 October 2021

Published online: 13 December 2021 